
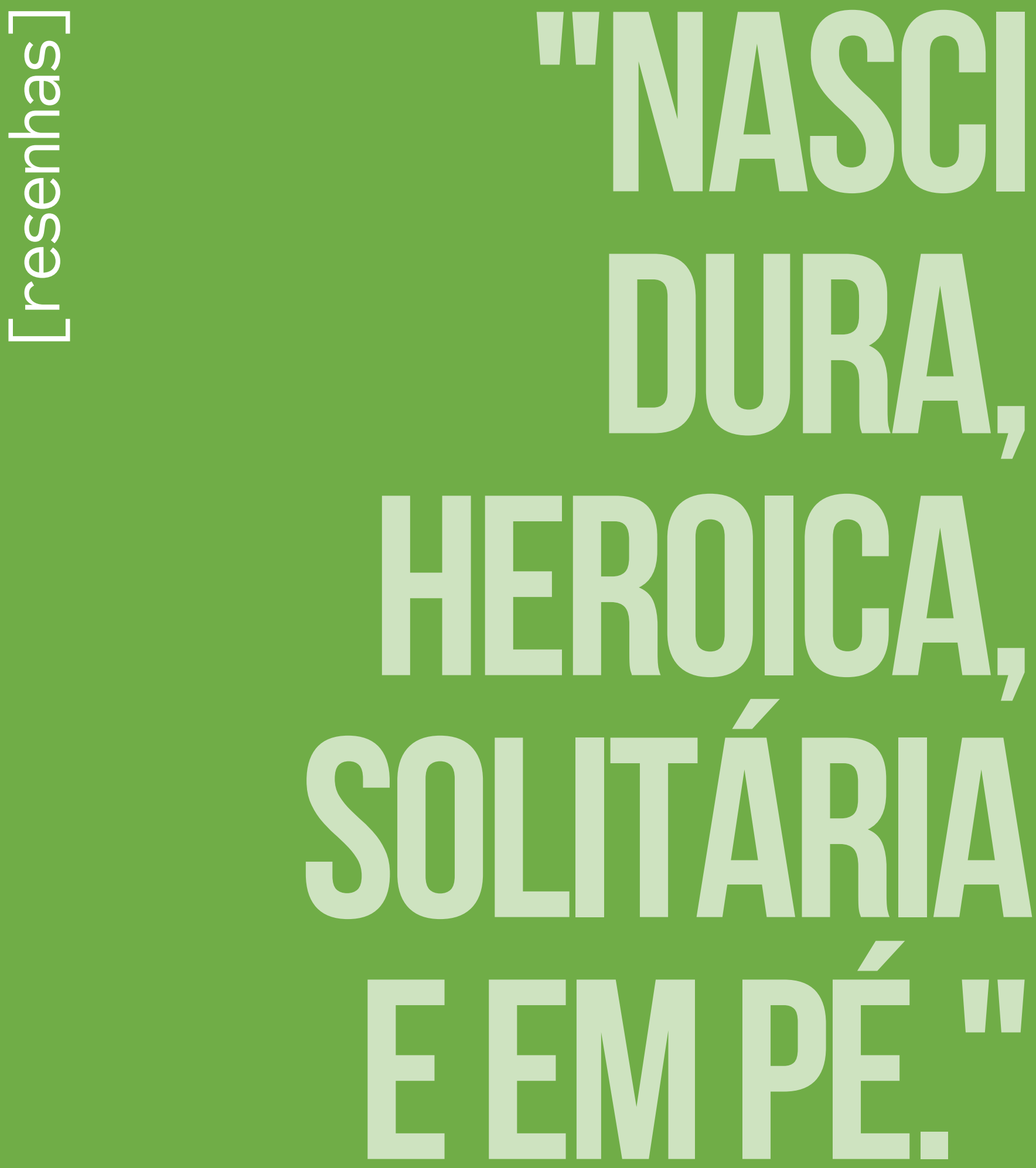

C farice Lispecto? 


\section{Mulheres artistas: um paradoxo (ainda) necessário}

Women artists: a (still) necessary paradox

Histórias das mulheres: artistas até 1900

Curadoria: Julia Bryan-Wilson, Lilia

Schwarcz e Mariana Leme.

Museu de Arte de São Paulo, São Paulo, SP, Brasil.

De 23 de agosto a 17 de novembro de 2019. 
Gabriela Rodrigues Pessoa de Oliveira ${ }^{1}$

ORCID: https://orcid.org/0000-0002-6654-9157

Em 2011, Ana Paula Cavalcanti Simioni escreveu uma resenha sobre o catálogo da exposição Elles@centrepompidou: Artistes femmes dans la collection du Musée National d'Art Moderne ${ }^{2}$, publicada no Cadernos Pagu. No texto intitulado A difícil arte de expor mulheres artistas, a autora abordou exposições anteriores voltadas a artistas mulheres ou a publicação de livros, como o Modern woman, de autoria de Cornelia Butler e Alexandra Schwartz, publicado pelo Museu de Arte Moderna de Nova York, em 2010, dedicado ao levantamento e análise das obras de mulheres artistas presentes na coleção do museu. . Para Simioni, a sincronia dos eventos apontava para o "consistente indício do impacto que os estudos sobre as relações entre arte e gênero realizados no ambiente acadêmico foram finalmente capazes de gerar no campo das instituições artísticas" (SIMIONI, 2011, p. 376).

Se a passagem da primeira para a segunda década dos anos 2000 serviu como marco para prestigiadas instituições realizarem uma revisão dos lugares sociais pré-definidos e da absorção dos gêneros tanto no ensino artístico quando na sua visibilidade institucional, no Brasil, essa onda tardaria um pouco mais para se fazer sentir ${ }^{3}$. A partir de 2015, no entanto, mostras privilegiando o trabalho artístico realizado por mulheres tomariam fôlego a partir da exibição de Mulheres artistas: as pioneiras (1880-1930), curada pela própria Ana Paula Simioni e por Elaine Dias, apresentada na Pinacoteca de São Paulo ${ }^{4}$. Desde então, não só grandes exposições tomaram forma, como mostras individuais de mulheres artistas tiveram um olhar privilegiado na programação dos museus. No Museu de Arte de São Paulo (Masp), talvez, o maior impulso para examinar essa questão tenha vindo da mostra Guerrilla Girls: Gráfica, 1985-2017, exibida na instituição em 20175. Em um destacado painel, doado pelas artistas ao museu, as ativistas faziam a incômoda pergunta: "As mulheres precisam estar

\footnotetext{
1 Mestre pelo Programa "Culturas e Identidades Brasileiras" do Instituto de Estudos Brasileiros da Universidade de São Paulo (2016). Desde 2013 atua como pesquisadora da Pinacoteca do Estado de São Paulo, na área de Acervo Artístico. E-mail: gabriela.pessoaoliveira@gmail.com. Lattes: http:// buscatextual.cnpq.br/buscatextual/visualizacv.do?id=K4498431T8.

Tradução nossa: Elles@centrepompidou: Artistas mulheres na coleção do Museu Nacional de Arte Moderna.

Faz-se necessário citar a mostra Contribuição da mulher às artes plásticas no país, realizada pelo MAM-SP, entre 1960 e 1961. Ver: CERCHIARO, Marina Mazze; SIMIONI, Ana Paula Cavalcanti; TRIZOLI, Talita. The exhibition 'Contribuição da mulher às artes plásticas no país' and the silence of Brazilian art criticism. Artl@s Bulletin 8, n. 1 (2019), artigo 14. Houve também a mostra Mulheres pintoras: a casa e o mundo, realizada em 2004, na Pinacoteca de São Paulo, com curadoria de Ruth Sprung Tarasantchi.

${ }^{4}$ Mulheres artistas: as pioneiras (1880-1930). Pinacoteca de São Paulo, de 13 de junho a 25 de outubro de 2015.

5 Entre 2016 e 2019, Masp realizou uma série de individuais de artistas mulheres, entre as quais destacamos Lygia Pape, Teresinha Soares, Wanda Pimentel, Maria Auxiliadora e Lucia Laguna, e a já citada Guerrilla girls.
} 
nuas para entrar no Museu de Arte de São Paulo?". Tal questão era motivada pela constatação de que apenas 6\% das artistas em exibição no acervo do Masp eram mulheres, em contrapartida, $60 \%$ dos nus expostos no mesmo local representavam mulheres, segundo estatística levantada em 2017. Esse dado evidencia como as instituições historicamente absorvem as mulheres em um lugar pré-definido, como objetos de representação e não como protagonistas do fazer artístico.

Examinar não apenas uma única história, inequívoca, mas diversas narrativas e percursos está no cerne da programação do Masp, que assim realizou as mostras Histórias da infância, Histórias afro-atlânticas e Histórias da sexualidade, antes de Histórias das mulheres e histórias feministas. Tal conceito fica evidente na fala da curadora-assistente, Isabella Rjeille:

A categoria mulher também não pode ser conceituada como única e universal, uma vez que é atravessada por diversos marcadores sociais, geográficos e temporais que transformam essa experiência. Também não há um consenso entre historiadoras, artistas e teóricas sobre a definição do que conformaria uma arte feminista, tampouco sobre a existência de modos de produção e estéticas essencialmente femininas. (RJEILLE, 2019, p. 187)

Nesse sentido, Histórias das mulheres, segundo o catálogo da mostra, apresenta trabalhos de mulheres de diversas nacionalidades, desde o século 1 até o XIX. Na mostra, dispostos em ordem cronológica, nomes consagrados como Artemisia Gentileschi, Lavinia Fontana, Sofonisba Anguissola, Elizabeth Vigée Le Brun, Berthe Morisot, Mary Cassatt e Marie Bashkirtseff, entre outras, dividiam o espaço com nomes pouco conhecidos, como as brasileiras Francisca Manoela Valadão, cuja mostra trazia a única pintura conhecida de sua autoria, e a mexicana Maria Ibarrola, de quem não são conhecidos nem mesmo os dados biográficos. Seguindo na esteira do reconhecimento, ou na ausência dele, uma série de produções têxteis, de autorias não identificadas, mas que se supõe de mulheres, faz par com as telas.

Uma profusão de retratos e obras captando ambientes internos demonstra alguns constrangimentos em relação ao pleno exercício das artes e as limitações do ir e vir impostas aos sujeitos femininos. Cenas de gênero e/ou históricas são escassas. Para a realização de telas com essas temáticas, caras no fim do século XVIII até o século XIX, o acesso aos estudos da figura humana era fundamental, sendo este um dos impasses duradouros em relação à admissão de mulheres no ensino artístico formal (DIAS; SIMIONI, 2015). Desse modo, as condições para o desenvolvimento do "gênio" artístico em homens, coincidentemente, eram muito mais generosas e favoráveis do que para as mulheres.

Por outro lado, por meio de detalhes presentes nas obras, pode-se acessar pistas dos papéis sociais esperados das mulheres e os seus limites. Cenas que possivelmente representam preparativos para noivados e casamentos, a viuvez expressa na austeridade das vestes negras, a educação e o papel das mulheres em relação às crianças e noções de recato presente nas roupas, gestos e nas posturas. Além disso, são visíveis os recortes sociais e de classe presentes em adereços e joias e na maestria da representação dos tecidos finos e rústicos. 
Autorretratos em que as artistas não se deixam captar na elaboração de seu ofício, como os de Abigail de Andrade, Sofonisba Anguissola, Louise Breslau, Leonor Almeida Portugal de Lorena e Lencastre e Vigée Le Brun, que embora pose com seus pincéis e paleta, representam muito mais a beleza, a elegância e a apresentação de uma pintora da corte do que a marcação de seu ofício ${ }^{6}$.

Para além dos recortes sociais e de classe, algumas artistas exprimem constrangimentos em relação a ocupar lugares socialmente limitados. Nesse sentido, uma das obras mais demonstrativas do evidente desconforto feminino burguês é a tela de Emily Osborn, Nameless and friendless. "The rich man's wealth is his strong city, etc", Provérbio X, 15, de 1857. Nesta obra está retratada uma jovem em vestes negras, no centro da composição, em um estabelecimento que comercializa estampas e desenhos. A jovem está acompanhada de uma criança, um possível irmão, que carrega uma grande pasta, que poderia arquivar outras obras. A cena flagra o momento em que o negociante, um homem, avalia uma tela em suas mãos, com expressão dúbia. Nesse mesmo momento, a artista capta a expressão de outros homens presentes no local, que assistem a cena. A jovem não consegue conter o seu constrangimento e abaixa os olhos na direção do chão, enquanto os dedos denunciam o seu acanhamento ao puxarem um cordão. Temos algumas hipóteses para essa obra. A jovem em vestes negras, encarnando a sobriedade da vestimenta vitoriana, pode se tratar de uma artista tentando vender os seus trabalhos, e pode ter sido realizada com base no romance Self-control, de Mary Brunton (1778-1818), em voga na época, como sugere o texto que acompanha a obra. Nessa hipótese, a jovem do quadro pode ser associada à representação da protagonista Laura, uma artista que, em busca de melhorar a condição da família, tenta vender os seus trabalhos aos negociantes de arte. Porém, as visitas aos estabelecimentos mostram-se todas infrutíferas. Outra possibilidade é que se trata de uma jovem viúva, talvez com o filho, que, desse modo, tenta superar possíveis privações financeiras negociando seus próprios trabalhos, se ela for artista, ou de seu falecido marido. De todo modo, por meio do título Sem nome e sem amigos, Osborn trabalha o desamparo e a inadequação feminina em um ambiente comercial, em uma cidade dominada por homens.

Outro ponto da exposição é a inserção de têxteis, predominantemente anônimos, de diversos períodos e localidades, dispostos como obras. Esse saber fazer encontrado em bordados, rendas e diversos tipos de teceduras presentes em mantos, lenços, colchas e capas era permitido e, na divisão social dos trabalhos, incentivado como atividades "femininas", alocadas no âmbito doméstico. Embora tomassem considerável tempo das mulheres e fossem também trabalhos "manuais", assim como os trabalhos de arte, pelas circunstâncias da formação do sistema artístico, nunca alcançaram um status de arte, como aponta Julia Brian-Wilson:

\footnotetext{
Com exceção da obra da artista mexicana Guadalupe Carpio de Mayora, Autorretrato com su familia, da segunda metade do século XIX, em que se representa no ofício, com sua família.

Tradução presente no catálogo da mostra: Sem nome e sem amigos. A prosperidade do homem rico é a sua cidade forte, etc.
} 


\begin{abstract}
No âmbito dos modelos euro-americanos convencionais de história da arte, os trabalhos têxteis, assim como as técnicas de tecelagem, bordado, crochê e renda, não foram normalmente considerados "belas" artes elevadas, mas ocupam uma zona em outro lugar (no reino do vernáculo ou amador) ou abaixo dos chamados gêneros altos de pintura e escultura. A despeito do fato de que muita habilidade e inovação entram nessas formas de artesanato, eles foram relegados a posições secundárias. Isso está inextricavelmente associado à percepção dos têxteis manuais como sendo trabalho das mulheres. (BRYAN-WILSON, 2019, p. 197)
\end{abstract}

Nesse ponto, as curadoras questionam esse fato, aproximando as composições têxteis dos suportes artísticos ditos tradicionais:

Não obstante, ao apresentá-las lado a lado, insiste-se no fato de que o trabalho têxtil anônimo e as pinturas de gênero assinadas constituem registros paralelos - não idênticos, mas análogos - do fazer feminino, e contestam a consolidação das histórias da arte masculinistas, que não permitiram que esses paralelos fossem levados a sério. (BRYAN-WILSON, 2019, p. 197-198)

Discursos sociais e uma profusão de ideias disseminados por especialistas apartaram a mulher de atividades laborais e intelectuais no passado (EHRENREICH; ENGLISH, 2003). Obviamente, essas recomendações também atendem aos recortes de classe, visto que as mulheres mais pobres não podiam escolher segui-las e absorviam trabalhos bastante pesados e exaustivos. Além disso, a exposição nos faz pensar que, por mais que caminhemos em relação às "descobertas" de artistas femininas, esses "encontros" são ainda privilegiados pelo lugar social ocupado pelas autoras. Por mais que o acesso das mulheres, de um modo geral, fosse restrito, aquelas que alcançavam o ingresso no fazer artístico não eram as mais marginalizadas socialmente. Observando as biografias levantadas no catálogo, é evidente que a maioria das mulheres artistas provém de estratos privilegiados, quando não nascem em famílias de artistas, o que facilita o contato com o ofício, assim como aumenta as chances de se acessar esses trabalhos e registros de atuação.

No caso brasileiro, fica evidente que essas artistas são provenientes ao menos de uma pequena burguesia. Esse recorte por si só já evidencia o eclipsamento de muitas mulheres que não teriam como sequer pensar em seguir a carreira de artistas. Na exposição, chama a atenção que apenas duas telas representem indivíduos negros. Uma delas é Cena de mercado, de Francisca Manoela Valadão. Na tela em questão, uma profusão de frutas tropicais, legumes, verduras e animais encontra-se caoticamente ordenada, seja no chão, seja empilhada em barris, tomando a imensidão da cena pictórica. Ao fundo da composição, no lado esquerdo, vemos mulheres negras sentadas, a maioria vestindo turbantes, sendo que algumas encaram o espectador. Do lado direito, uma mulher branca parece escolher legumes, enquanto uma mulher negra gesticula. 
A cena de mercado em questão, dada à natureza dos frutos e às trabalhadoras negras, escravas de ganho ou libertas, invariavelmente, soa-nos familiar como uma cena brasileira. A composição, com predomínio de cores terrosas, e a disposição exuberante dos alimentos quase tornam essas mulheres invisíveis, passariam facilmente despercebidas a olhos distraídos.

Em outra tela, de Abigail de Andrade, $A$ hora do pão, temos um registro do cotidiano carioca. Na frente de um velho sobrado, há um vendedor de pães em meio a diversas crianças. Apoiado em um portão, vemos um homem negro com os pés descalços, referência clara ao recente passado escravocrata, quando uma das marcas exigidas dos escravos era andar com os pés diretamente no solo. No âmbito da exposição, marcada por representações de mulheres brancas, essas presenças discretas, porém potentes, ainda escancaram as questões discriminatórias e de acesso das populações negras que por anos marcaram e ainda marcam o país.

Voltando ao texto de Ana Paula Simioni, a análise sobre a exposição do Pompidou, a autora aponta para um dilema curatorial: o paradoxo de se expor somente artistas mulheres. Analisando um capítulo do catálogo da mostra francesa, Simioni traz à tona o texto de Camile Morineau intitulado Elles@centrepompidou: un appel à la difference ${ }^{8}$. Segundo Simioni:

O museu optou por expor apenas mulheres, mas não para demonstrar que existe uma arte feminina ou um objeto feminista, mas ao contrário, para explodir as supostas unidades e estereótipos. Alicerçando-se nas teorias de Joan Scott (1996), retoma-se a existência de dois universalismos contraditórios na origem do pensamento republicano francês. Primeiramente, aquele dos direitos políticos individuais, universalista, igualitário e válido para os homens [...] e, por outro lado, o universalismo da diferença sexual, considerada como diferença "natural" entre homens e mulheres, a qual subsidiaria expectativas de atuações sociais diversas para cada sexo. Como defendeu a autora, na história contemporânea da França o universalismo da diferença prevaleceu sobre o dos direitos naturais, a ponto do indivíduo abstrato não ser neutro, mas masculino. (SIMIONI, 2011, p. 380-381)

E conclui:

Assim, a conclusão de Scott é reivindicada por Morineau como legitimadora dos partidos curatoriais tomados: a fim de almejar o universalismo, é preciso paradoxalmente tomar a palavra, para tanto fazendo-o em nome da diferença das mulheres, a mesma que, num primeiro momento, as conduziu à exclusão. É justamente essa a contradição de reivindicar a particularidade com vistas a promover a visibilidade das artistas, a multiplicidade de suas potencialidades, suscitando uma autocrítica dos atores e instituições, que permitirá um objetivo ainda maior, o de promover uma outra história da arte possível. (SIMIONI, 2011, p. 381)

\footnotetext{
8 Tradução nossa: Elles@centrepompidou: um chamado à diferença.
} 
Tomando o trecho acima, podemos pensar que a suposta "neutralidade" do indivíduo, que, no limite, é um sujeito masculino, poderia encontrar um paralelo na palavra "artista". Dada a imensa amplitude de nomes repetidos nas monografias e nas coleções de história da arte, vê-se que, na imensa maioria dos casos, tratam-se de homens, brancos, heteronormativos e europeus. Partindo disso, qualquer artista ou grupo que não se encaixe nessa descrição ganha automaticamente um complemento: artistas mulheres, artistas negros, artistas indígenas. Quando esses grupos poderão ser denominados somente artistas? Para responder essa pergunta, as iniciativas expositivas contribuem, mas não bastam. Há que se ter políticas revisionistas de aquisição de obras que privilegiem grupos ainda minoritários com o intuito de que possam fazer par com os nomes consolidados da história da arte. Há uma anedota de que a obra de Eva Gonzalès, Um camarote no teatro dos italianos, frequentemente era confundida com a obra de Manet. Não era, portanto, uma questão de qualidade que diferenciava a artista de seu mestre. Desse modo, Mulheres artistas mostra-nos um horizonte, mas anuncia que o caminho ainda é bastante longo.

\section{Referências}

DIAS, Elaine; SIMIONI, Ana Paula Cavalcanti. Mulheres artistas: as pioneiras (1880-1930). São Paulo: Pinacoteca do Estado, 2015.

EHRENREICH, Barbara; ENGLISH, Deirdre. Para seu próprio bem: 150 anos de conselhos de especialistas para as mulheres. Rio de Janeiro: Rosa dos Tempos, 2003.

SIMIONI, Ana Paula Cavalcanti. A difícil arte de expor mulheres artistas. Cadernos Pagu, Campinas, n. 36, p. 375-388, junho 2011. Disponível em: http://www.scielo.br/scielo. php?script=sci_arttext\&pid=S0104-83332011000100014\&lng=en\&nrm=iso. https://doi. org/10.1590/S0104-83332011000100014. Acesso em: 2 fev. 2020.

BRYAN-WILSON, Julia; LEME, Mariana; RJEILLE, Isabella; SCHWARCZ, Lilia Moritz. Histórias das mulheres, histórias feministas. São Paulo: MASP, 2019. 